\title{
Preface
}

Islamic hagiography is a rich, expansive repository of religion, history, and culture. As with so many areas of the still-young field of Islamic studies, countless written sources have yet to be rediscovered and edited, and translation remains in most instances a still-more-remote prospect. A cursory search for "Muslim Saints" in the Library of Congress online catalog turns up over two hundred titles of fairly recent vintage, the vast majority of which are (evidently) by Muslims writing in non-European languages. Though the topic is by no means a museum piece, material is still largely inaccessible to the wider reading public. With few exceptions, European and American scholars interested in the hagiographical sources have used the documentation to reconstruct historical and cultural contexts, institutional developments, and the careers of major individual figures.

The majority of scholarly analysis, originating particularly in the disciplines of history, anthropology, and political science, has focused on the history of Sufism. But the story these sources tell is a much bigger one, and a study of Friends of God must look to a broader canvas than that of Sufism. The immense patrimony of Islamic hagiographical sources has yet to generate adequate interest in the windfall of insights into the religious and ethical life of Muslims that await discovery in these sources. Interrogating the sources about "what really happened" is, of course, an essential ingredient in understanding them. However, we must also let the sources speak for themselves, even-perhaps especially-when they seem to venture into the realm of the preternatural. To do so by no means calls for a naïve, uncritical reading of this often multilayered material. It simply acknowledges that though many written sources offer potentially important historically verifiable data, much hagiographical material offers a great deal more. Even when an author appears to have slipped off the straight path of "fact" onto the mucky byways and quick sands of 
credulity, we can learn something from such sources. Here the challenge is to find a solid methodological basis for evaluating the less verifiable claims of many hagiographical sources. In this book, I suggest such a broad method.

Storytelling remains the most effective way to tell a story. This statement is no mere tautology. The larger story is how and why accounts of colorful religious figures have captured the attention of countless millions of Muslims for nearly fourteen hundred years. To explore these questions, we need to situate written hagiographical sources in the broader context of the humanities and appreciate their distinctive and even unique features. To tell the larger story, we must fashion a set of tools for appreciating how the numerous smaller stories communicate the ineffable. Great poetry has some potential to inform readers about the life and times of the poet, but scholars generally acknowledge that this potential is very limited. Readers of a great poem do not ordinarily feel constrained to ask whether the poem's subject "really happened." A successful poem reveals far more about the inner life of the poet-and that of his or her reader. As in poetry, imagination in the hagiographies I look at here is an essential key to letting the smaller tales unfold the larger narrative.

This book tells stories about a host of characters whom many Muslims have regarded as astonishing despite their ordinariness. In the chapters that follow, I hope to offer a way of understanding how those characters have functioned in the lives of Muslims of diverse cultural, social, economic, and political contexts. Questions of historicity, though generally shifted to the background, have their place here, particularly in looking at institutional developments. But above all, readers need to become travelers in the realms of the religious imagination as well as in those of space and time. This book offers a broad introduction to the global phenomenon of Islamic personalities who function as embodiments or personifications of sanctity. With such a broad thematic overview, one cannot also provide in a single volume the kind of in-depth historical and literary analysis necessary to appreciate the many faces of individual Friends in the varied accounts of them and to understand the ways in which diverse historical contexts have shaped these multifaceted portrayals. A companion anthology now in preparation, will provide further literary and historical context and supply additional depth and breadth through multiple examples of hagiographical texts in over a dozen languages.

An important organizational-methodological premise here is that Islamic hagiography is not limited to accounts of the post-prophetic figures called "Friends of God" in the narrower, more technical sense of the term. Stories of the prophets, from Adam to Muhammad, as well as accounts of exem- 
plary individuals of the earliest generations of Muslims and the $\mathrm{Sh}_{1}{ }^{\mathrm{c}} \overline{1}$ imams of the subsequent two and a half centuries or so, are all considered here as part of a continuum of tradition and lore that has perdured down to our day.

This volume is both premature and long overdue. It is premature in the sense that much detailed work remains to be done in the study of individual texts and regional traditions of hagiography. Scholarly analysis of the vast caches of material, in well over a dozen major languages from across the globe, is still in its infancy. And the next level of needed scholarship, diachronic studies of primary sources' interpretations of individual Friends across time and over cultural and linguistic boundaries, has similarly just begun. This book is also long overdue, for several reasons. Given the historical and cultural pervasiveness of the lives and stories of Friends of God, a need exists for a useful and evocative thematic overview that approaches the story of Islam as a global tradition. In addition, the increasing tendency of extremist interpretations of Islam to denounce Friends of God and all they stand for, as part and parcel of the wholesale rejection of history and culture, increases the importance of presenting an alternate narrative-a narrative cultivated and preserved by countless Muslims for many centuries.

\section{THE STRUCTURE OF THE BOOK}

A brief introductory overview of Islamic hagiography in all its color and variety begins the story. Three perspectives then give structure to the unfolding narrative. Part 1, gathers accounts of key moments and aspects of the literary life experiences of Friends of God from birth to death. Major thematic elements begin to emerge with a look at nativity and infancy narratives, often sprinkled with the miraculous (chapter 1 ). Stories of many of the Friends begin a bit later than infancy, often starting with a moment of "conversion" (chapter 2) that establishes a new tone in the Friend's relationship to God from then on (chapter 3). A common theme in many life stories is that of the miracle or saintly marvel, and one can again discern a wide range of specific themes and subtypes among stories of such extraordinary events (chapter 4 ). Intimations of mortality provide an unmistakable counterbalance to the spectacular, as manifest in accounts of ordinary human foibles and frailties. Friends also die, and remembrances of their earthly departures are essential to their stories (chapter 5 ).

Situating individual prophets and Friends' life cycles in broader contexts is the overriding concern of part 2. These contexts include the larger collectivity of saintly lives and the history of the many local, regional, and even global 
communities that have called these Friends their own. In the stories in this section, Friends of God relate to their respective societies and local communities in a variety of ways. They function as moral and spiritual exemplars and engage in the world as advocates for their people, warriors, and missionaries. Some Friends choose to stay on the margins of society, and others, particularly women, are relegated to the fringes through no choice of their own (chapter 6). Many Friends of God have ties to a variety of institutions, whether as founders or as eponymous ancestors. Some have contributed to the development of organizations of spiritual seekers, generally known as Sufis. Most are identified to some degree with important burial places (chapter 7). In addition, hagiographical accounts link Friends of God to many important holy sites, creating interlocking networks of sacred geographies. The presence of exemplars of devotion and holiness has been an important ingredient in many Muslims' sense of the larger world and their place in it (chapter 8). So much information about Friends of God is historical and often quite ancient. But hundreds of millions of Muslims across the globe today still calibrate their moral and spiritual compasses by the lives and deeds of the great ones (chapter 9).

Finally, part 3 addresses the challenge of interpreting the larger implications of this treasure house of tales. Chapter ıo provides an outline of major hagiographic literary forms and functions, dipping into the sources for clues to how their authors intended them to be used and understood. Large theoretical issues about the theological, cosmological, and psychological dimensions of the accounts are the focus of chapter 11 .

\section{A NOTE ON USING THE BOOK}

Pedagogically speaking, I have designed the four sections of the book to build gradually in complexity and technical precision. The introduction describes a broad historical development, highlighting several types of literary material, but does so in fairly general terms. The five chapters of part 1 rely almost entirely on anecdotes, arranged thematically, so that the reader can gradually make acquaintance with major figures and become familiar with episodes from the lives of diverse personalities. Part 2's four chapters blend increasingly noticeable, but still generally unthreatening, elements of historical data and theoretical concepts into the narratives. Finally, part 3 shifts from narrative elements to focus almost entirely on background issues.

I situated these two chapters at the end of the book rather than at the beginning because many readers might be daunted by an immediate immersion in theory and technical terminology. Readers already broadly familiar with the 
Islamic religious tradition, including teachers who want to incorporate this volume into formal courses in Islamic studies, might want to begin with chapters 10 and 11 , thereby establishing a theoretical and methodological framework for reading the stories in parts 1 and 2. Alternatively, teachers might opt to tap into segments of the last two chapters selectively, in the course of reading parts $I$ and 2 (referring, for example, to chapter 11 's section on miracles and marvels when students read chapter 4 ).

My choice of a generally thematic structure neither means to suggest, nor reflects the conclusion, that Islamic hagiography is essentially a patchwork of formulaic accounts. Some patterns do emerge from a broad study of the material, and my decision to focus on many of those common themes and "types" of story or character is largely pedagogical in intent. This volume's primary goal is to allow readers to make an introductory acquaintance with a vast subject. In no way do I mean to sidestep the methodological complexity and sophistication a deeper study of the subject requires, and which mark the works of so many scholars on which I have relied.

The remarkable hagiographical works I discuss in this book are far more than the sum of the engaging tales gathered here; their structures and plans are far more substantial than would be possible in mere collections of interchangeable narrative units and plots; and their subjects are ultimately far more subtle and rounded than one can tell from the sometimes hit-and-miss effect of a thematic approach. I hope that these stories and themes will kindle in readers a desire to fill in the countless gaps by further pursuing this most rewarding tributary to the greater Islamic tradition.

\section{RESOURCES AND TECHNICALITIES}

Research for this volume has relied on a relatively limited store of primary sources, both in their languages of origin and in translation, as well as a much larger trove of secondary research. My non-English access to the former is confined to works in Arabic and Persian, and in the latter instance, to publications in French, German, Spanish, and Italian. (Though I give most titles both in their original languages and in English, my presentation of a title in English is strictly for the reader's information and does not necessarily mean that the work is available in translation.) Throughout the book, I have drawn especially on sources that tend to recount the stories of the Friends in generally fulsome narratives and less so on those that compile hadithlike briefer anecdotes and sayings. I confess a personal bias toward 'Attār's Persian Tadhkirat al-awliy $\bar{a}$, truly a masterpiece of narrative art and a vastly influ- 
ential work in its own right. Paul Losensky has done a most welcome translation of much of this text for the Paulist Press Classics of Western Spirituality series, but when the present volume went to press, that work had not yet appeared. Much as I would have liked to acknowledge in greater detail the countless intertextual connections among the great hagiographies, I have limited such cross-references because of constraints of time and space. Serious attention here to that dimension of the larger hagiographical story would have required a multivolume product.

In the hopes of making this volume useful to scholars interested in pursuing the subject further, I have included a considerable amount of bibliographical material. To maximize utility of this material and make the most efficient use of space, I have provided bibliographical information in endnotes rather than in a formal bibliography, presorting relevant entries as cleanly as possible according to historical, thematic, and geographical context.

Technical terms often require some clarification or special consideration in translation. I have leaned toward calling the book's many paradigmatic figures "Friends of God" but have also retained the most commonly used "nonIslamic" renderings of wal̄ and walàya - namely, "saint" and "sainthood" as well as cognates such as "saintly" and "saintliness," and analogous terms such as "sage" or "righteous or authentic one" (some of which appear as synonyms or subcategories of the Islamic notion of Friend of God). My first bias rests on the conviction that because the paradigmatic figures in this book exhibit a number of characteristics in Islamic sources not found in the sources of Christianity or other traditions, one needs a way to acknowledge their uniqueness. At the same time, the desirability of avoiding cumbersome circumlocutions calls for some flexibility in the use of terms.

Transliteration always poses certain technical problems, but in a book whose subject covers as many linguistic and cultural contexts as this one does, the challenges are huge. My overarching concern has been to achieve a consistency in transliteration that would facilitate reading and cross-referencing. To that end, I have privileged a modified standard system of transliterating Arabic and have tried to use that system consistently where the language of origin (especially of personal or place names) was Arabic or Persian. I have also used this system for technical terms of Arabic or Persian origin that are in other linguistic contexts (e.g., if a Malay source mentioned an "eviden-

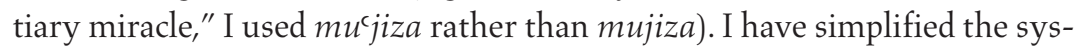

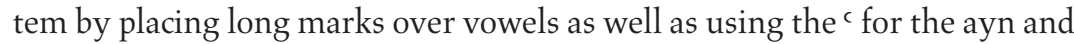
' for the hamza, but I have not included the sub- and supralinear dots with consonants. My rationale is that whereas the nonspecialist reader will find clues to correct pronunciation in the macrons, only specialists would appre- 
ciate the sub-/supralinear apparatus that betokens more difficult variations in pronunciation. With those specialists in mind, however, I have retained a full system of transliteration in the index. Terms that are now in wide usage, such as shaykh, hadith, and imam are spelled according to the conventions of Merriam-Webster's Collegiate Dictionary, Eleventh Edition.

I have included death dates for individuals, when they were readily available, in both the Hijrī lunar and Gregorian solar date systems, in the index. I did so to make chronological data readily available without interrupting the flow of reading. Dual dates also appear throughout the text: a date expressed in the Islamic lunar calendar is given first (Hijrī, i.e., after the Hijra of 622), followed by a slash and the date in the Gregorian calendarfor example, $1 / 622$. Finally, I use the term Islamicate to refer to societies, cultures, and artifacts deeply influenced by the religious tradition of Islam but not "Islamic" in the strictly religious sense.

\section{ACKNOWLEDGMENTS}

I wish to thank fellow specialists in Islamic religious studies Ahmet Karamustafa of Washington University in St. Louis and Frederick Denny of the University of Colorado for their generosity in reading and commenting on drafts of the book. I am indebted to a host of other colleagues in Islamic religious studies of the American Academy of Religion Islamic Studies Section for dozens of helpful comments, suggestions, and bits of advice about resources and topics related to hagiography. To the scores of other scholars whose relevant works I cite or list in the notes, I express my gratitude for their studies in various regions, individual figures and organizations, and individual hagiographical texts, without which a book of this kind would be impossible.

In addition, my thanks go especially to Catherine Scine of Saint Louis University for her consistent and patient assistance in researching and editing the large volume of material that forms the basis of this book. I thank also Christine Baudin, Lisa Marie Duffield, Danny Dunivan, and Tomas O'Sullivan, members of a seminar on medieval hagiographies at Saint Louis University in the fall of 2005, who along with Catherine Scine provided much helpful criticism of the evolving drafts of the volume; and Ben $\mathrm{O}^{\prime}$ Connor and Robert Porwoll of Saint Louis University for their assistance during the final phase of manuscript preparation and indexing. Special thanks to Reed Malcolm and Kalicia Pivirotto (Religious Studies) and Rachel Berchten (editorial), all at the University of California Press, and to Adrienne 
Harris for their outstanding attentiveness and assistance in the completion of this and two earlier publications.

For help in securing permissions for illustrations, I thank especially Elaine Wright and Sinead Ward of the Chester Beatty Library in Dublin and Nahla Nassar of the Nasser D. Khalili Collection of Islamic Art. I am grateful to Saint Louis University for a Provost Faculty Research Leave during which to advance writing on the initial drafts, SLU Mellon Grant funding to support art-program research, Summer Research Award funds for art-program expenses, and a sabbatical leave during which to complete the volume.

And, as always, my deepest gratitude and appreciation go to my spouse, Mary Pat, for her constant support, wisdom, and good humor as this project unfolded. 